\title{
Screening for Diabetic Eye Disease among Samoan Adults: A Pilot Study
}

\author{
V. Swetha E. Jeganathan - Tim Langford - Lucilla Ah-Ching Sefo • \\ Alex W. Hewitt · Nitin Verma
}

Received: April 7, 2017 / Published online: May 17, 2017

(C) The Author(s) 2017. This article is an open access publication

\begin{abstract}
Introduction: The purpose of this study was to determine the prevalence of diabetic retinopathy in Samoa by piloting a retinal photography screening programme.

Methods: We performed a cross-sectional study of patients with diabetes who presented to the Tupua Tamasese Meaole eye clinic in Apia, Samoa, between May 2011 and September 2011. Study approval was granted by the National Health Service Board of Samoa, the Monash University Human Research Ethics Committee, and the study adhered to the Tenets of the Declaration of Helsinki. Following informed
\end{abstract}

Enhanced content To view enhanced content for this article go to http://www.medengine.com/Redeem/ 1028F06022C1308B.

V. S. E. Jeganathan

Kellogg Eye Center, University of Michigan,

Ann Arbor, MI, USA

T. Langford

Monash University, Melbourne, VIC, Australia

L. Ah-Ching Sefo

National Health Service of Samoa, Tuasivi, Samoa

A. W. Hewitt · N. Verma

Department of Ophthalmology, Royal Hobart

Hospital, Hobart, TAS, Australia

A. W. Hewitt · N. Verma $(\bowtie)$

Hobart Eye Surgeons, Hobart, TAS, Australia

e-mail: nitver3@gmail.com consent, data collection included patient demographics [age, area of residence (rural or urban)], type of diabetes, length of time since diagnosis, most recent random blood sugar and blood pressure levels. The subjects had three 45-degree retinal photographs taken in each eye with the Canon CR6-45NM camera. All gradable photographs were assessed for the presence of diabetic retinopathy or macular oedema using the International Clinical Diabetic Retinopathy Severity Scale and the International Clinical Diabetic Macular Oedema Severity scale, respectively.

Results: Two hundred and fourteen eyes from 107 subjects were examined during the study period, all of whom had type 2 diabetes mellitus. Diabetic retinopathy was present in $53.3 \%$ $(114 / 214)$ of eyes, with $14.5 \%$ having proliferative retinopathy and $7.5 \%$ with severe non-proliferative retinopathy. Also, 25.2\% (54/ 214) had some evidence of macular oedema with $11.7 \%(25 / 214)$ requiring treatment. A statistically significant relationship existed between the length of time since diagnosis and the severity of both retinopathy $(p<0.001)$ and macular oedema $(p=0.031)$. Blood pressure more than $150 / 85 \mathrm{mmHg}$ was associated with higher levels of diabetic retinopathy $(p=0.03)$ and macular oedema $(p=0.02)$.

Conclusion: A comprehensive diabetic retinopathy screening programme is much needed in Samoa given the high prevalence of diabetic eye disease. 
Keywords: Diabetic macular oedema; Diabetic retinopathy; Retinal photography; Screening; Samoa

\section{INTRODUCTION}

Diabetes Mellitus (DM), a major health pandemic, affects an estimated 285 million people globally and is projected to affect 366 million people by 2030 [1-3]. One of diabetes' costliest aspects involves the detection and treatment of its complications [4, 5]. In Australia, Wright et al., studied a hypothetical patient with blindness due to diabetic retinopathy (DR) and estimated the direct annual cost incurred by both the government and community would be $\$ 17,701$ (range \$9669-26,720) [6]. Detecting DR changes early and providing timely interventions decrease the risk of DR progression and risk of permanent sight-threatening disease [7]. Implementing DR screening programs using retinal photography is a cost-effective intervention, for reducing ongoing clinic visits and visual rehabilitation, as well as improving patients' quality of life [8-10].

A particularly high prevalence of DM exists in the Pacific Island nations $[11,12]$. Samoa is a small South Pacific Island nation with a population of 193,000 divided between two large islands [13]. The capital, Apia, is located on the island of Upolo and is home to the country's only major hospital [Tupua Tamasese Meaole, (TTM) Hospital]. The main health concerns in Samoa are diabetes, obesity, and cardiovascular disease, all of which are increasing in prevalence [14-16]. Collins et al. compared the rates of DM in Apia over a 13-year period (1978-1991) and found the prevalence amongst men rose from $8.1 \%$ to $9.5 \%$; while in women it rose from $8.2 \%$ to $13.4 \%$ [17]. Another Samoan survey conducted in 2002 found that the prevalence of DM had almost doubled to $23.1 \%$ [18]. The current burden of diabetes in Samoa is more than 25\% of the total population [19]. Furthermore, despite the cost-effectiveness of early DR detection, Samoa currently has no regular DR screening programme $[10,20]$. We performed a pilot study to explore the feasibility of DR screening in Samoa that, if implemented, could potentially reduce the burden of DR through earlier diagnosis and treatment.

\section{METHODS}

A cross-sectional study of patients with DM was conducted at the eye clinic at TTM hospital, between May 2011 and September 2011. TTM hospital has one of two eye clinics in Samoa and the only one on the island of Upolu. All diabetic patients, presenting to TTM's eye clinic in the 4-month time frame as stated above, were asked their willingness to participate in DR screening. Patients were provided an information sheet detailing the study. Following informed consent, subjects were asked their demographics [age, area of residence (rural or urban)], and medical history. For the purposes of this study, any area of Samoa other than Apia, was considered rural [17]. Medical information obtained included type of DM, length of time since DM diagnosis, most recent random blood sugar level (BSL), blood pressure (BP, $\mathrm{mmHg}$ ), and previous ophthalmic history.

The current practice at the TTM eye clinic is to dilate the pupils in all patients with DM for fundoscopy. Therefore, the participants had their retinal photos taken through dilated pupils with a Canon CR6-45NM retinal camera (Canon Incorporated, Tokyo, Japan, 2005). Three 45-degree retinal photographs were taken in each eye, centred on the macular, the disc and temporal to the macula. The photographs were digitally stored and assessed for quality. Copies of the grading report were kept in the case notes. All photos that were readable were assessed for the presence of DR and diabetic macular oedema (DMO). If either were present, the photos were graded according to the International Clinical DR Severity Scale and the International Clinical DMO Severity Scale [21]. Photos that were "unreadable" were forwarded to a consultant ophthalmologist in Australia.

All subjects were advised of their level of DR at the time of examination, instructed how to control their risk factors, and when to return for re-examination. Subjects found to have severe non-proliferative DR or proliferative DR (PDR) were referred to a visiting ophthalmologist for 
assessment and treatment. Some complicated cases were referred to an ophthalmologist in New Zealand.

Statistical analysis was performed using SPSS (TM, version 19, 2011). Data collected was first analysed by eye, i.e., each eye was treated as separate and individual from the participant's other eye. All demographic information for each patient was the same for each eye; however, the grade of DR and DMO may have been different. Data relating to the prevalence of DR and DMO was analysed as a whole followed by various sub-group analyses. The subgroups that were assessed included: gender, length of time since diagnosis, area of residence of the patient, BP, and reported BSL. Secondly, data was analysed in terms of each patient, i.e., both eyes were considered in the same patient with the worse eye being taken as the participant's DR or DMO level. Analysis of Variance (ANOVA) tests were performed to compare the levels of DR and $\mathrm{DMO}$ in these groups. For continuous variables (length of time since diagnosis, BP, visual acuity and reported BSL) Chi squared trend testing was used to compare DR and DMO grades with nominal variables such as BP, gender and location of residence. Probability values of $<0.05$ were considered to be statistically significant. Study approval was granted by the National Health Service Board of Samoa, the Monash University Human Research Ethics Committee, and the study adhered to the Tenets of the Declaration of Helsinki.

\section{RESULTS}

\section{Demographic Data}

Two hundred and fourteen eyes from 107 subjects were examined during the study period, all of whom had type 2 diabetes. The median age of participants was 60 years and $45.6 \%(49 / 107)$ were male. The area of residence was determined for 74 people, of which 31 (43.6\%) lived in rural areas. The mean BP of subjects in our study was $152 / 87 \mathrm{mmHg}$, and the mean BSL was $62 \mathrm{mmol} / \mathrm{L}$. Table 1 outlines the basic demographic data of subjects in the study.
Table 1 Demographic data of the study population

\begin{tabular}{ll}
\hline Median age (years) & 60 \\
Male (\%) & 45.8 \\
Median age of males (years) & 59 \\
Median age of females (years) & 61 \\
Median years since diabetes mellitus diagnosis & 10 \\
Mean reported blood sugar levels (mmol/L) & 11.0 \\
$n=62$ & 151.5 \\
Mean systolic blood pressure $(\mathrm{mmHg}) n=61$ & 87.3 \\
Mean diastolic blood pressure $(\mathrm{mmHg}) n=61$ & \\
\hline
\end{tabular}

\section{Retinal Photographs}

As part of the study, $85.5 \%$ (183/217) eyes were graded for both their level of DR and DMO. It was found that $14.5 \%$ had unreadable photographs, mainly due to media opacities, such as cataracts, but were included in the final analyses.

\section{Diabetic Retinopathy}

DR was present in $53.3 \%(114 / 214)$ of eyes, with $14.5 \%(31 / 214)$ having PDR (18 treated previously) and $7.5 \%(16 / 214)$ with severe NPDR. Only $32.2 \%(69 / 214)$ of all eyes photographed showed no signs of DR. The length of time since DM diagnosis was an important factor in the development of DR (Fig. 1). Figure 2 shows the relationship between $\mathrm{BP}$ and grade of DR. When analysing BP sub-groups using a Chi squared test for trends, a statistically significant difference was found $(p=0.03)$. When ANOVA testing was performed, a statistically significant relationships existed between length of time since DM diagnosis and higher grades of DR $(p<0.0001)$; and higher systolic BP (when taken as a continuous variable) and higher grades of DR $(p=0.002)$.

\section{Diabetic Macular Oedema}

In this study, $11.7 \%(25 / 214)$ had DMO requiring treatment; $25.2 \%(54 / 214)$ had some 


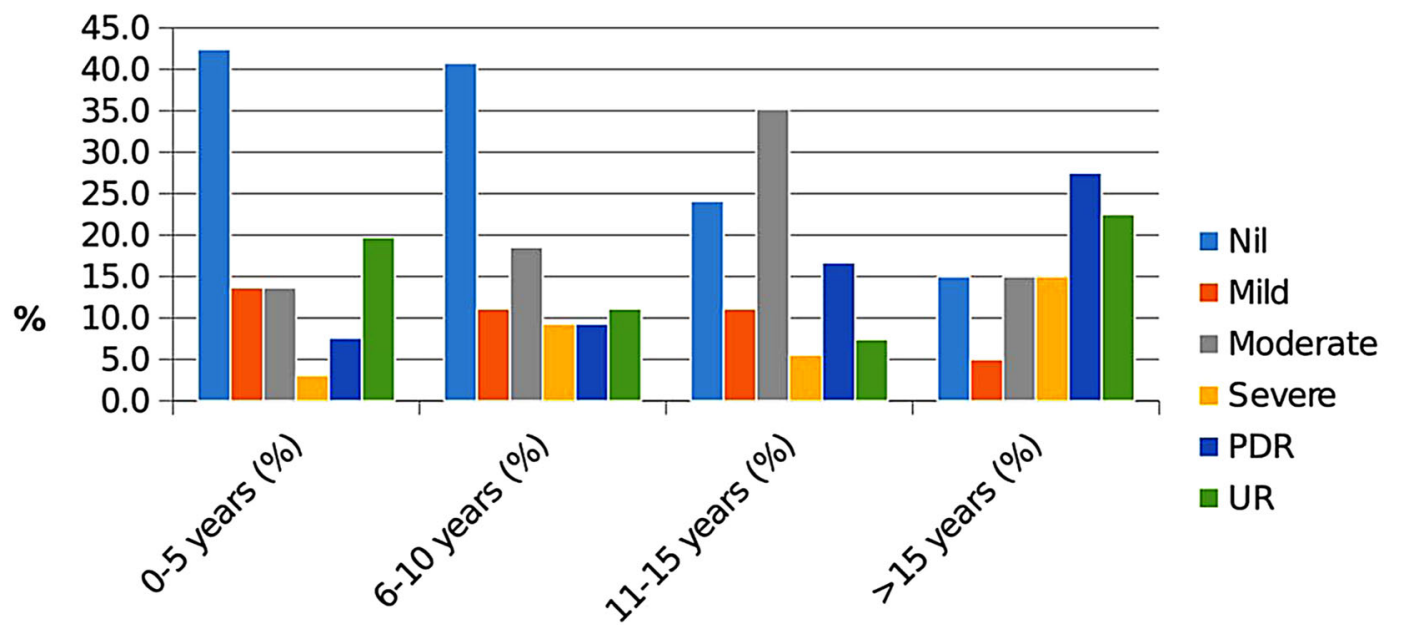

Length of time since diagnosis

Fig. 1 Grade of diabetic retinopathy according to length of time since diagnosis of diabetes mellitus. The $y$-axis indicates the percentage of people with diabetic retinopathy and the $x$-axis indicates the length of time since diagnosis of diabetes

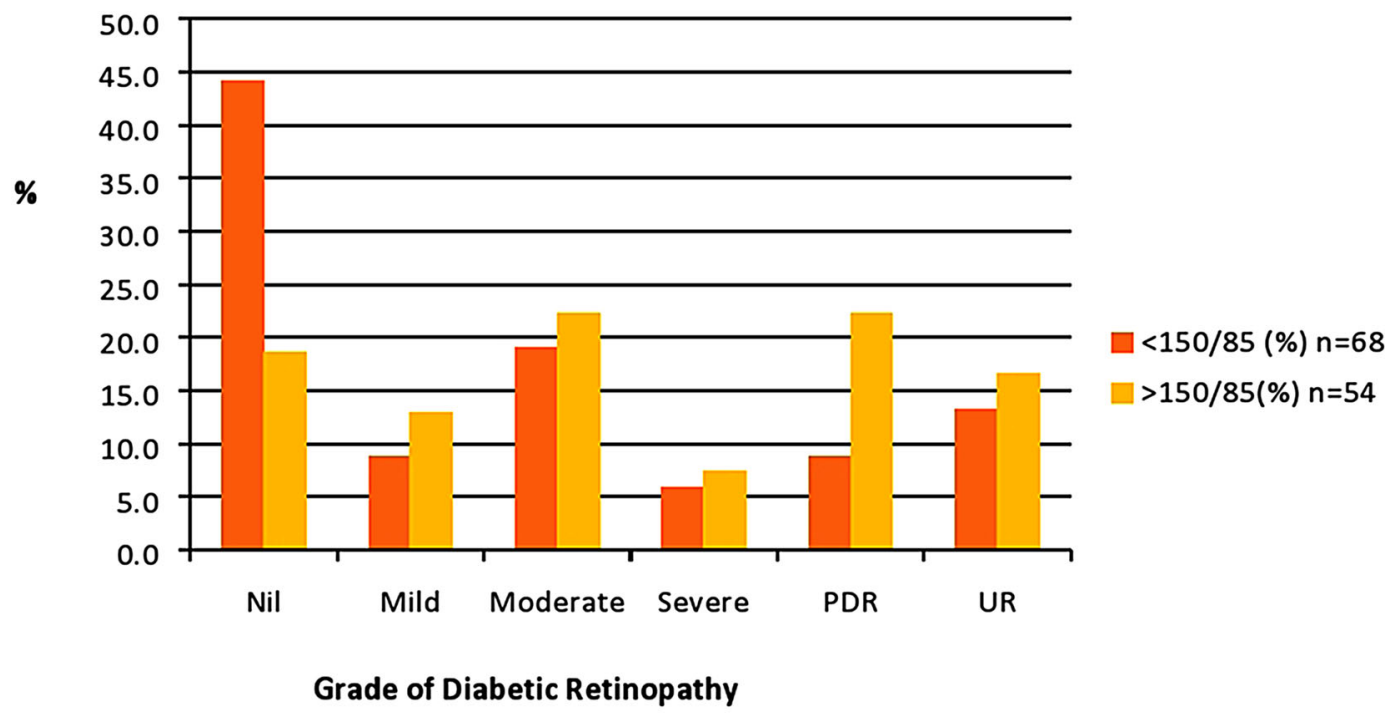

Fig. 2 Blood pressure compared to diabetic retinopathy grade. The $y$-axis indicates the percentage of people with high blood pressure and the $x$-axis indicates the grade of diabetic retinopathy

evidence of DMO, and 60.3\% (129/214) of eyes were free of any signs of DMO. Table 2 shows the distribution of the different grades of DMO with gender. Chi squared tests found a statistically significant relationship between higher grades of DMO and the female gender $(p=0.05)$, as well as high grades of DMO and BP $>150 / 85 \mathrm{~mm} / \mathrm{Hg} \quad(p=0.02)$. ANOVA testing found a statistically significant relationship between increased length of time since DM diagnosis and a higher grade of DMO $(p=0.031)$. However, the ANOVA test did not show a statistically significant relationship between the grade of DMO and the reported BSL level $(p=0.66)$. 
Table 2 Distribution of diabetic macular oedema grades

\begin{tabular}{lccc}
\hline $\begin{array}{l}\text { Diabetic macular } \\
\text { oedema level }\end{array}$ & All & Male & Female \\
\hline Nil & 129 & 68 & 61 \\
& $(60.3 \%)$ & $(69.4 \%)$ & $(52.6 \%)$ \\
Mild & $10(4.7 \%)$ & $6(6.1 \%)$ & $4(3.4 \%)$ \\
Moderate & $19(8.9 \%)$ & $4(4.1 \%)$ & 15 \\
& & & $(12.9 \%)$ \\
Severe & 25 & 11 & 14 \\
& $(11.7 \%)$ & $(11.2 \%)$ & $(12.1 \%)$ \\
Urgent treatment & 31 & $9(9.2 \%)$ & 22 \\
& $(14.5 \%)$ & & $(19.0 \%)$ \\
Total & 214 & 98 & 116 \\
\hline
\end{tabular}

\section{Location of Residence and Diabetic Eye Diseases}

The proportion of DR in the rural group was $58.1 \%(36 / 62)$ compared with $36.5 \%(40 / 86)$. However, this relationship was not found to be statistically significant following Chi squared tests for trend $(p=0.38)$. DMO also had a higher prevalence amongst rural participants of this study when compared to urban participants. Chi squared tests for trend, again, did not find a statistically significant relationship between location of residence and the grade of DMO $(p=0.19)$.

\section{DISCUSSION}

Our study revisited DR in Samoa for the first time in 20 years, providing a valuable snapshot of the current ocular health of the local diabetic population. We found the prevalence of DR in Samoa to be much higher (53.3\%) than previous reports (range $8.1 \%$ to $23 \%$ ) [17, 18]. Our figure increased further to $65.4 \%$ when the number of people with DR in one or both eyes was considered and $31.1 \%$ of our study population had DMO. Another earlier Samoan study found that DR caused blindness and low vision in $7.9 \%$ and $13.4 \%$ of patients [22]. Keefe et al. noted that DR ranked among the leading causes of visual impairment in Pacific Island nations [23]. Our rates of DR and DMO were much higher than recent studies' findings in neighbouring Pacific Islands such as Fiji (21.5\%) and Solomon Islands (38\%) (Table 3). These high figures may be due to the poor control of the risk factors for DR amongst Pacific Islanders $[11,24]$. Studies from New Zealand have found that Pacific Islanders were less likely to achieve good glycaemic control and had higher BP readings, both of which are important risk factors for DR [25-27].

In our study, a statistically significant relationship existed between the length of time since diagnosis and the severity of both DR $(p<0.001)$ and DMO $(p=0.031)$. Unfortunately, the length of time that a person has DM is a risk factor that cannot be modified [28]. The

Table 3 Comparison of recent diabetic retinopathy and diabetic macular oedema studies in the Pacific Islands

\begin{tabular}{lllll}
\hline Disease severity & $\begin{array}{l}\text { Our study } \\
\boldsymbol{n}=\mathbf{1 0 7}(\mathbf{\%})\end{array}$ & $\begin{array}{l}\text { Collins, Samoa (1991) } \\
{[\mathbf{1 5}] \boldsymbol{n}=\mathbf{8 8}(\mathbf{\%})}\end{array}$ & $\begin{array}{l}\text { Qoqonokana, Solomon Islands } \\
\mathbf{( 2 0 1 0 )}[\mathbf{3 8}] \boldsymbol{n}=\mathbf{5 0}(\mathbf{\%})\end{array}$ & $\begin{array}{l}\text { Brian, Fiji (2010) } \\
{[\mathbf{3 9}] \boldsymbol{n}=\mathbf{2 2 2}(\mathbf{\%})}\end{array}$ \\
\hline $\begin{array}{l}\text { All diabetic } \\
\text { retinopathy }\end{array}$ & 53.3 & 43.2 & 38 & 21.5 \\
$\begin{array}{c}\text { Proliferative } \\
\text { diabetic } \\
\text { retinopathy }\end{array}$ & 14.5 & 4.6 & 5 & 1.9 \\
$\begin{array}{l}\text { All diabetic } \\
\text { macular oedema }\end{array}$ & 25.2 & & & \\
$\begin{array}{c}\text { Severe diabetic } \\
\text { macular oedema }\end{array}$ & 11.7 & N/A & 19 & 4.5 \\
\hline
\end{tabular}


Wisconsin Epidemiologic Study of DR showed that the severity of retinopathy was related to a longer duration of diabetes [29]. The Newcastle DR study found that after 30 years, $87 \%$ to $90 \%$ of patients had DR, with an $8 \%$ annual risk of developing DR [30, 31]. Other studies have found a statistically significant yearly odds ratio for the development of DR (i.e., 1.1 and 1.06) $[32,33]$.

Blood pressure was an important risk factor for the development and progression of DR in our study. Hypertension was a major problem in our study population, with patients' having an average BP of $152 / 90$, which exceeds the recommended levels of 130/80 for diabetic patients [34]. Our study showed a statistically significant relationship between high systolic BP and high grades of DR $(p=0.002)$, and BP higher than $150 / 85 \mathrm{mmHg}$ was associated with higher levels of DR $(p=0.03)$ and DMO $(p=0.02)$. A continuous relationship exists between $\mathrm{BP}$ and the risk of DR [34]. A rise in systolic and diastolic BP of $10 \mathrm{mmHg}$ has been associated with a 3-20\% increased risk of DR [35]. Good BP control reduces the risk of developing DR $[34,35]$. The UKPDS found that a decrease of $10 \mathrm{mmHg}$ in BP led to a $34 \%$ decrease in the risk of DR progression $(p=0.004)$ [36]. Tight BP control (BP $<150 / 85 \mathrm{mmHg}$ ) reduced DR progression by $34 \%$ and visual acuity loss by $47 \%[34,36]$.

In Samoa, many live with undiagnosed diabetes: those who are eventually diagnosed, experience advanced complications [14]. Of the vast majority of participants screened with the retinal camera, a large proportion with disease required treatment highlighting the real need for a formal DR screening program in Samoa. Similar equipment as what we used in our study could be utilized as part of a telemedicine programme to identify sight-threatening disease $[37,38]$. When in doubt about the diagnosis, the captured image could be sent electronically to a specialist ophthalmologist for diagnosis and advice on management [37, 39].

Limitations of our study should be noted. DR assessment was based on three 45-degree fundus photographs through dilated pupils, similar to those used in previous Samoan studies $[17,18]$. Performing seven 30-degree fields-the internationally recognized gold-standard was not feasible given our limited resources [40]. The subjects sampled may not be truly representative of the wider Samoan population. Subjects were not randomly selected and selection bias is an important consideration. Although many persons with diabetes attended the eye clinic for reasons unrelated to DR, others presented with cataracts and symptomatic DR. Thus, we may have overestimated the severity of DR in our Samoan population. It is also possible we under-represented people with mild/asymptomatic DR, or with social or health problems that did not have hospital access. The small number of subjects $(n=107)$ limited our ability to show statistical significance differences between groups (type 2 error), especially in the subgroup analysis. Finally, due to high cost and poor availability of glucometers, most diabetics in Samoa obtained a single random blood glucose check at 3 monthly intervals rather than measuring their HbA1c blood levels [41].

\section{CONCLUSION}

Our pilot study showed that DR is a serious problem in Samoa. A larger, more detailed cross-sectional population-based study is needed to investigate the increasing prevalence of DR in Samoa. Having the resources to measure HbA1c levels, in addition to DR retinal screening among a random population sample from both rural and urban areas would provide a more accurate picture of the true prevalence of diabetes and DR in Samoa. Assessing various risk factors, including behavioural reasons for poor control of DM, hypertension, obesity, and treatment compliance, would provide invaluable insights into the potential targets for public health interventions.

\section{ACKNOWLEDGEMENTS}

The authors thank Dr. Marcel Favilla, Professor Jill Keefe, Dr. Limbo Fiu, Dr. Tia Vaai, staff of the TTM eye clinic, and patients recruited in the study. No funding or sponsorship was received for this study or publication of this article. 
All named authors meet the International Committee of Medical Journal Editors (ICMJE) criteria for authorship for this manuscript, take responsibility for the integrity of the work as a whole, and have given final approval for the version to be published.

Disclosure. V. Swetha E. Jeganathan, Tim Langford, Lucilla Ah-Ching Sefo, Alex W. Hewitt, and Nitin Verma have nothing to disclose.

Compliance with Ethics guidelines. The study conformed with the Helsinki Declaration of 1964, as revised in 2013, concerning human rights, and Springer's policy concerning informed consent has been followed.

Data Availability. The datasets during and/ or analyzed during the current study are available from the corresponding author on reasonable request.

Open Access. This article is distributed under the terms of the Creative Commons Attribution-NonCommercial 4.0 International License (http://creativecommons.org/licenses/ by-nc/4.0/), which permits any noncommercial use, distribution, and reproduction in any medium, provided you give appropriate credit to the original author(s) and the source, provide a link to the Creative Commons license, and indicate if changes were made.

\section{REFERENCES}

1. Federation ID. IDF diabetes atlas. 4th ed. Brussels: International Diabetes Federation; 2009.

2. Wild S, Roglic G, Green A, Sicree R, et al. Global prevalence of diabetes: estimates for the year 2000 and projections for 2030. Diabetes Care. 2004;27(5):1047-53.

3. Leasher JL, Bourne RR, Flaxman SR, et al. Global estimates on the number of people blind or visually impaired by diabetic retinopathy: a meta-analysis from 1990 to 2010. Diabetes Care. 2016;39(9):1643-9.
4. Scotland G, McKeigue P, Philip S, et al. Modelling the cost-effectiveness of adopting risk-stratified approaches to extended screening intervals in the national diabetic retinopathy screening programme in Scotland. Diabet Med. 2016;33(7):886-95.

5. Ting DS, Cheung GC, Wong TY. Diabetic retinopathy: global prevalence, major risk factors, screening practices and public health challenges: a review. Clin Exp Ophthalmol. 2016;44(4):260-77.

6. Wright SE, Keeffe JE, Thies LS. Direct costs of blindness in Australia. Clin Exp Ophthalmol. 2000;28(3):140-2.

7. Lin S, Ramulu P, Lamoureux EL, et al. Addressing risk factors, screening, and preventative treatment for diabetic retinopathy in developing countries: a review. Clin Exp Ophthalmol. 2016;44(4):300-20.

8. Jones S, Edwards RT. Diabetic retinopathy screening: a systematic review of the economic evidence. Diabet Med. 2010;27(3):249-56.

9. Holt RI. Diabetic retinopathy: a success story for screening. Diabet Med. 2016;33(7):863.

10. Tapp RJ, Svoboda J, Fredericks B, Jackson AJ, et al. Retinal photography screening programs to prevent vision loss from diabetic retinopathy in rural and urban Australia: a review. Ophthalmic Epidemiol. 2015;22(1):52-9.

11. Cheng MH. Asia-Pacific faces diabetes challenge. Lancet. 2010;375(9733):2207-10.

12. Sundborn G, Metcalf PA, Gentles D, et al. Ethnic differences in cardiovascular disease risk factors and diabetes status for Pacific ethnic groups and Europeans in the Diabetes Heart and Health Survey (DHAH) 2002-2003, Auckland New Zealand. N Z Med J. 2008;121(1281):28-39.

13. Central I, Agency. World Fact Book: Samoa Langly CIA; 2011. www.cia.gov/library/publications/theworld-factbook/geos/ws.html. Accessed Feb 22, 2017.

14. Lin S, Naseri T, Linhart C, Morrell S, et al. Trends in diabetes and obesity in Samoa over 35 years, 1978-2013. Diabet Med. 2016.

15. Rao M, DePue JD, Dunsiger $S$, et al. Long-term impact of a community health worker intervention on diabetes control in American Samoa. Prev Chronic Dis. 2015;12:E180.

16. Siaki LA, Loescher LJ, Ritter L. A cultural perspective of Samoans' perceived risk of cardiovascular disease and diabetes. J Cardiovasc Nurs. 2012;27(6):468-75. 
17. Collins VR, Dowse GK, Plehwe WE, et al. High prevalence of diabetic retinopathy and nephropathy in Polynesians of Western Samoa. Diabetes Care. 1995;18(8):1140-9.

18. McMurray C. Samoa, a situation analysis of children, women and youth. Fiji: UNICEF Pacific Office; 2006.

19. Leng DBS, Cheema S. A decentralized primary healthcare model based upon a cost-effective patient data system that includes remote districts and villages in Samoa. Samoa Med J. 2010;2:35-7.

20. Lees J, McCool J, Woodward A. Eye health outreach services in the Pacific Islands region: an updated profile. N Z Med J. 2015;128(1420):25-33.

21. Wu L, Fernandez-Loaiza P, Sauma J, et al. Classification of diabetic retinopathy and diabetic macular edema. World J Diabetes. 2013;4(6):290-4.

22. Ramke J, Brian G, du Toit R. Eye disease and care at hospital clinics in Cook Islands, Fiji, Samoa and Tonga. Clin Exp Ophthalmol. 2007;35(7):627-34.

23. Keeffe JE, Konyama K, Taylor HR. Vision impairment in the Pacific region. Br J Ophthalmol. 2002;86(6):605-10.

24. Li Y, Liao Y, Fan A, et al. Asian American/Pacific Islander paradox in diabetic retinopathy: findings from the behavioral risk factor surveillance system, 2006-2008. Ethn Dis. 2010;20(2):111-7.

25. Foliaki S, Pearce N. Prevention and control of diabetes in Pacific people. BMJ. 2003;327(7412):437-9.

26. Tomlin AM, Tilyard MW, Dawson AG, et al. Health status of New Zealand European, Māori, and Pacific patients with diabetes in 242 New Zealand general practices. N Z Med J. 2006;119(1235).

27. McKergow E, Parkin L, Barson DJ, et al. Demographic and regional disparities in insulin pump utilization in a setting of universal funding: a New Zealand nationwide study. Acta Diabetol. 2016.

28. Cheung N, Mitchell P, Wong TY. Diabetic retinopathy. Lancet. 2010;376(9735):124-36.

29. Klein R, Knudtson MD, Lee KE, et al. The Wisconsin Epidemiologic Study of Diabetic Retinopathy: XXII the twenty-five-year progression of retinopathy in persons with type 1 diabetes. Ophthalmology. 2008;115(11):1859-68.
30. Mitchell P, Moffitt P. Update and implications from the Newcastle diabetic retinopathy study. Aust N Z J Ophthalmol. 1990;18(1):13-7.

31. Marshall SM, Flyvbjerg A. Prevention and early detection of vascular complications of diabetes. BMJ. 2006;333(7566):475-80.

32. Zhang X, Saaddine JB, Chou C-F, et al. Prevalence of diabetic retinopathy in the United States, 2005-2008. JAMA J Am Med Assoc. 2010;304(6):649-56.

33. Raman R, Vaitheeswaran $\mathrm{K}$, Vinita $\mathrm{K}$, et al. Is prevalence of retinopathy related to the age of onset of diabetes? Sankara Nethralaya Diabetic Retinopathy Epidemiology and Molecular Genetic Report No. 5. Ophthalmic Res. 2011;45(1):36-41.

34. Rajalakshmi R, Prathiba V, Mohan V. Does tight control of systemic factors help in the management of diabetic retinopathy? Indian J Ophthalmol. 2016;64(1):62-8.

35. Gallego PH, Craig ME, Hing S, et al. Role of blood pressure in development of early retinopathy in adolescents with type 1 diabetes: prospective cohort study. BMJ. 2008;337:a918.

36. Stearne MR, Palmer SL, Hammersley MS, et al. Tight blood pressure control and risk of macrovascular and microvascular complications in type 2 diabetes: UKPDS 38. Br Med J. 1998;317(7160):703-13.

37. Gupta A, Cavallerano J, Sun JK, et al. Evidence for telemedicine for diabetic retinal disease. Semin Ophthalmol. 2017;32(1):22-8.

38. DeBuc DC. The role of retinal imaging and portable screening devices in tele-ophthalmology applications for diabetic retinopathy management. Curr Diabetes Rep. 2016;16(12):132.

39. Sim DA, Mitry D, Alexander P, et al. The evolution of teleophthalmology programs in the United Kingdom: beyond diabetic retinopathy screening. J Diabetes Sci Technol. 2016;10(2):308-17.

40. Zimmer-Galler IE, Kimura AE, Gupta S. Diabetic retinopathy screening and the use of telemedicine. Curr Opin Ophthalmol. 2015;26(3):167-72.

41. DePue JD, Rosen RK, Seiden A, et al. Implementation of a culturally tailored diabetes intervention with community health workers in American Samoa. Diabetes Educ. 2013;39(6):761-71. 